\title{
NÚCLEO AMPLIADO DE SAÚDE DA FAMÍLIA E ATENÇÃO BÁSICA: ANÁLISE DO PROCESSO DE TRABALHO
}

\author{
FAMILY HEALTH AND PRIMARY HEALTH CARE EXPANDED \\ SUPPORT CENTER: ANALYSIS OF THE WORK PROCESS
}

\begin{abstract}
Arthur Grangeiro do Nascimento iD (0000-0002-1119-8505) ${ }^{1}$, Joselma Cavalcanti Cordeiro iD (0000-0002-6844-4658) ${ }^{2}$
${ }^{1}$ Fundação Oswaldo Cruz, Instituto Aggeu Magalhães, Recife, Pernambuco, Brasil.

<arthurgn@hotmail.com>

${ }^{2}$ Universidade de Pernambuco, Faculdade de Ciências Médicas, Recife, Pernambuco, Brasil.
\end{abstract}

Resumo O artigo tem o objetivo de analisar o processo de trabalho de uma equipe do Núcleo Ampliado de Saúde da Família e Atenção Básica localizado em um município de Pernambuco. Trata-se de um estudo de caso com enfoque qualitativo, de caráter analítico-descritivo. As técnicas empregadas para a coleta de dados foram os grupos focais e mapas analíticos; para organização e análise, adotou-se a técnica do Discurso do Sujeito Coletivo. A análise do processo de trabalho revelou concepções no discurso da equipe de um 'dever ser' pautado no que é preconizado pelo Ministério da Saúde. Entretanto, foram identificados os seguintes aspectos: há pouco êxito em executar o apoio matricial; não há sucesso na construção de pactuações sobre o processo de trabalho; o trabalho é fragmentado e com foco assistencialista; não há utilização de tecnologias de análise e intervenção familiar e populacional. Observouse, também, escassa prática de planejamento das ações. Isso revela uma atuação distante do que se concebe como adequada pela própria equipe. Fatores problemáticos, internos e externos à equipe foram identificados. Indicase partir de uma análise do processo de trabalho realizada pela própria equipe, contribuindo para o alcance de maior resolutividade.

Palavras-chave atenção primária à saúde; trabalho em saúde; pessoal de saúde; Estratégia Saúde da Família; pesquisa qualitativa.
Abstract The present article has the goal of analyzing the work process of a team at the Family Health and Primary Health Care Expanded Support Center located in a municipality in the state of Pernambuco, Brazil. It is a case study with a qualitative focus and an analytical-descriptive nature. The techniques employed for the data collection were focus groups and analytical maps; for the organization and analysis, we adopted the technique of the Discourse of the Collective Subject. The analysis of the work process revealed in the discourse of the team conceptions regarding a 'must be' guided by what is recommended by the Brazilian Ministry of Health. However, the following aspects were identified: there is little success in the execution of the matrix support; there is no success in the development of agreements about the work process; the work is fragmented and has a focus on welfare; and there is no use of the technologies for analysis and family and populational intervention. We also observed that the planning of actions was rarely performed. This reveals a work that differs from what is considered adequate by the very same team. Problematic factors within and without the teams were also identified. We recommend beginning with an analysis of the work process that is to be performed by the very same team, which will contribute to reach more solutions.

Keywords primary healthcare; work in health; health personnel; family health strategy; qualitative research. 


\section{Introdução}

O Núcleo de Apoio à Saúde da Família (Nasf), criado pela portaria n. 154/2008, constitui-se como mais um esforço de reestruturação do processo de trabalho em saúde. Após a aprovação e publicação, pelo Ministério da Saúde, da portaria n. 2.436, de 21 de setembro de 2017, a qual deu origem à nova versão da Política Nacional de Atenção Básica, o Nasf passou a se chamar Núcleo Ampliado de Saúde da Família e Atenção Básica (Nasf-AB) (Brasil, 2017).

O Nasf-AB tem o objetivo de apoiar a Estratégia de Saúde da Família (ESF) e outras modalidades de equipes de atenção básica, ampliar o escopo de atuação desses grupos, proporcionar uma retaguarda especializada nas ações de saúde e de aumentar a resolutividade do cuidado em saúde na atenção básica. O modo de organizar o processo de trabalho do Nasf-AB é norteado, principalmente, pela lógica do apoio matricial, clínica ampliada, cogestão e por ferramentas que subsidiem o trabalho como, por exemplo, o Projeto de Saúde no Território e o Projeto Terapêutico Singular (Brasil, 2014).

A necessidade de esforços para reestruturação do trabalho em saúde revelase nos resultados de análises do modelo de atenção à saúde vigente no Brasil, que se caracteriza, hegemonicamente, por sua forma fragmentada de atenção, centrada na doença e não no indivíduo posicionado em um dado contexto (Ceccim e Feuerwerker, 2004; Bedrikow e Campos, 2014).

Ao sair de um discurso mais genérico e especificando essa problematização para os Nasfs-AB, a situação é confirmada ao se identificarem diversos fatores que dificultam e desafiam o seu processo de trabalho. Entre eles, há a lógica de atuação ambulatorial, a resistência por parte das equipes de saúde da família em aceitar o modelo de apoio matricial e o maior foco em atividades assistenciais em detrimento das ações de promoção da saúde e prevenção de doenças. Além desses fatores, há a não utilização de instrumentos de trabalho orientados para vigilância em saúde e planejamento, dificuldade de compreensão do trabalho do Nasf-AB tanto pelos profissionais do Núcleo como das equipes apoiadas, dentre outros. São evidências de dificuldades, limites e desafios relacionados ao processo de trabalho do Nasf-AB e que vêm sendo constatadas nos diferentes estados e regiões do Brasil (Vieira de Macedo et al., 2016; Lancman et al., 2013; Reis et al., 2016; Shimizu e Fragelli, 2016; Pasquim e Arruda, 2013; Barros, 2015; Moura e Luzio, 2014).

O desafio atual é a transformação do modo de produzir saúde, que deve implicar a reestruturação e organização do processo de trabalho dentro de uma perspectiva de transição tecnológica. Partindo-se desta visão, o trabalho seria centrado nas tecnologias das relações, possibilitando o acolhimento do usuário, e nas tecnologias que contribuíssem para um sistema integrado, de cuidado contínuo, focado na pessoa e na família, priorizando a promoção e 
prevenção de riscos e agravos à saúde. Desse modo, possibilitaria a resolutividade do trabalhador, a autonomização do usuário e o alcance dos objetivos preconizados para o Nasf-AB (Mendes, 2012; Merhy, 1997).

O presente estudo partiu da seguinte questão: Como é organizado o processo de trabalho de uma equipe do Núcleo Ampliado de Saúde da Família e Atenção Básica? Seu objetivo foi analisar o processo de trabalho de uma equipe do Nasf-AB localizada em um município do Estado de Pernambuco.

\section{Processo de trabalho em saúde e os Núcleos Ampliados de Saúde da Família e Atenção Básica}

O processo de trabalho em saúde teve seu conceito formulado por MendesGonçalves (1992) fundamentado na teoria marxista do trabalho. Ele é constituído por cinco elementos. O primeiro é o agente que irá executá-lo. O segundo é o objeto do trabalho, sobre o qual incide a ação do trabalhador e aquele que será transformado. O terceiro elemento é o produto; o quarto refere-se aos instrumentos ou meios do trabalho, os quais representam uma coisa ou um complexo de coisas que o trabalhador insere entre si mesmo e o objeto de trabalho. Esses instrumentos servem para dirigir a atividade do trabalhador sobre esse objeto. Por fim, o quinto elemento, que é a finalidade de toda ação. Esses cinco elementos são categorias de análise utilizadas para abordar e compreender certos aspectos da realidade, em específico, das práticas de saúde (Peduzzi e Schraiber, 2008; Mendes-Gonçalves, 1992).

Outros autores contribuem para a construção teórica do tema, trazendo a discussão sobre os tipos de instrumentos de trabalho em saúde que podem ser categorizados em materiais e imateriais. Detalhando essas categorias, têmse tecnologias duras (materiais), como seringa, máquinas etc.; tecnologias leve-duras (imateriais), que são saberes e conhecimentos estruturados; e tecnologias leves (imateriais), como sendo o ato de se relacionar com as pessoas. Ademais da classificação dos instrumentos de trabalho, discutem, também, sobre tipos de trabalho: o trabalho morto e o trabalho vivo. O primeiro é o trabalho já realizado, é quando se usa um objeto que é fruto de um trabalho anterior. O segundo é o trabalho que se realiza em ato (Franco e Merhy, 2008; Mendes-Gonçalves, 1992).

Hoje, o que caracteriza o modelo hegemônico de atenção à saúde é a centralidade na doença e o uso de tecnologias duras para a resolução dos problemas, em detrimento do trabalho em equipe, organizado sob a ótica da integralidade, com o emprego de tecnologias leves e leve-duras. Sinaliza-se a necessidade de ruptura com o modelo vigente e, para isso, é necessária a compreensão do processo de trabalho em saúde e todos os seus condicionantes pelos próprios trabalhadores, para que haja possibilidade de transformá-lo (Merhy, 2014; Merhy, 2013; Peduzzi, 2001). 
É com a perspectiva de ruptura com o atual modelo de atenção à saúde que se direciona o trabalho dos Núcleos Ampliados de Saúde da Família e Atenção Básica, ao menos em sua concepção, já que no cotidiano dos serviços se encontram práticas que não seguem a lógica preconizada para a Atenção Básica. Nesta medida, há uma variação de modelos de Nasf-AB relatados na literatura científica, cujas causas dessas variações são múltiplas. Elas vão desde a formação dos profissionais, passando pela lógica de organização das práticas adotadas pela gestão municipal, até determinações ideológicas, políticas e econômicas (Vieira de Macedo et al., 2016; Reis et al., 2016; Barros et al., 2015; Lancman et al., 2013).

$\mathrm{O}$ resultado dessa diversidade permite categorizações das equipes Nasf-AB, de acordo com determinadas características. Segundo Nascimento (2014), é

possível sistematizar três tipos de configurações: a primeira aproxima-se mais do modelo ideal, ou seja, o preconizado pelo MS, denominado de Nasf equipe matricial; o segundo tipo reflete a existência de configurações que apresentam ações assistenciais e técnico-pedagógicas, mas identifica-se uma priorização do atendimento ambulatorial em detrimento de outras ações conjuntas - intitulado Nasf equipe semimatricial; e o terceiro tipo apresenta um distanciamento intenso do objetivo do Nasf à medida que utiliza o apoio apenas como um acesso aos especialistas, fortalecendo, assim, o modelo Nasf assistencial-curativista (Nascimento, 2014, p. 156).

Desse modo, a análise do processo de trabalho do Nasf-AB deverá observar os aspectos que caracterizam suas práticas, tendo como parâmetro o modelo preconizado pelo Ministério da Saúde. Para tal, descreve-se sua organização e seus componentes a fim de visualizar a descrição e identificar os problemas. Diante desse cenário, é possível propor soluções para que o objetivo da produção do cuidado em saúde seja atingido, com o protagonismo dos próprios profissionais da equipe.

\section{Características e caminhos da análise do processo de trabalho do Nasf}

A presente pesquisa é um estudo de caso, com enfoque qualitativo, de caráter analítico-descritivo. Seu objeto de análise é o processo de trabalho de uma equipe Nasf-AB de um município de Pernambuco.

Caracteriza-se dessa forma porque seu objeto é um fenômeno contemporâneo, por ter a pergunta norteadora do tipo 'como', por não exigir controle sobre eventos comportamentais efetivos e por ser a interpretação de uma realidade no espaço de intersubjetividade. Esse encontro de subjetividades entre o pesquisador e os informantes do seu processo de trabalho ocorre 
pelas compreensões compartilhadas por meio de representações e significados de um fenômeno. A pesquisa qualitativa, pois, propõe-se a captar as pistas desse espaço complexo (Denzin e Lincoln, 2006; Uchimura e Bosi, 2002; Yin, 2010).

Os sujeitos da pesquisa foram os profissionais de um Nasf-AB, implantado no ano de 2010, responsável por apoiar nove equipes de saúde da família distribuídas em quatro Unidades Básicas de Saúde de um município de Pernambuco. O Nasf-AB em questão é composto por um assistente social, um nutricionista, um psicólogo, dois fisioterapeutas, um farmacêutico e um fonoaudiólogo. Quanto aos vínculos empregatícios, apenas um profissional da equipe possui vínculo estável por meio de concurso público, enquanto os demais têm contratos sem garantia de estabilidade. Em relação à formação especializada na área, dois profissionais possuem título de especialista em Saúde da Família, pelo Programa de Residência em Saúde da Família.

A análise do processo de trabalho dessa equipe foi operacionalizada por grupos focais em três momentos, com intervalo temporal de trinta dias entre eles. Nesses grupos, foram construídos mapas analíticos, que são instrumentos de análise do cotidiano dos serviços pelos próprios trabalhadores, propostos por Franco e Merhy (2013). Sua construção ocorreu em um debate coletivo, partindo-se de temas disparadores da discussão, que foram delineados por cada ator que se colocava. Esses mapas auxiliaram no registro in loco e na visualização gráfica da descrição do processo de trabalho, procedimento que facilitou a análise tanto pelos profissionais da equipe como, posteriormente, pelos pesquisadores.

Utilizado como uma técnica de coleta de dados, o grupo focal é um arranjo usado por investigações tanto na área da saúde como nas ciências sociais de maneira geral. Envolve indivíduos que tenham objetivos comuns e permite construir um espaço de discussão, reflexões e análises em profundidade de modo participativo e dialético, tornando possível a captação de concepções e experiências dos participantes (Backes et al., 2011).

Cada grupo focal abordou temas que contribuíram para a descrição e a análise do processo de trabalho. O primeiro grupo focal trabalhou três elementos do processo: os agentes, os instrumentos e a finalidade do trabalho do Nasf-AB. O segundo grupo debateu outros dois elementos: o objeto e o produto do trabalho do referido núcleo. E o terceiro - e último - grupo abordou questões sobre as dinâmicas do processo de trabalho e as subjetividades da equipe, como seus desejos, conflitos, o que consideram como atos inúteis ou indispensáveis nas atividades do Nasf-AB. Todo o processo foi gravado, transcrito e submetido à análise dos dados.

O procedimento utilizado para tratamento dos dados coletados foi a do Discurso do Sujeito Coletivo (DSC). É uma técnica de tabulação e organi- 
zação de dados qualitativos que permite agregar depoimentos sem reduzilos a quantidades. Consiste em analisar o material verbal dos discursos proferidos pelos participantes da pesquisa extraindo de cada um deles expressões-chave, ancoragens e ideias centrais semelhantes para compor discursos-síntese. A elaboração do DSC necessita de algumas figuras metodológicas (Lefèvre e Lefèvre, 2005; Lefèvre e Lefèvre, 2014), a saber: expressões-chave, ideias centrais, ancoragem e discurso do sujeito coletivo

As expressões-chave são fragmentos, trechos ou transcrições literais dos discursos que devem ser destacadas. Revelam a essência do depoimento. As ideias centrais são a descrição do sentido ou de um conjunto homogêneo de expressões-chave, o qual dará origem, posteriormente, ao discurso do sujeito coletivo. Ancoragem é o termo utilizado para revelar uma teoria, ideologia ou crença subjacente ao discurso. Discurso do sujeito coletivo é o discurso-síntese redigido na primeira pessoa do singular. Neste estudo, refere-se ao discurso que foi consenso da equipe, como se fosse uma pessoa. É construído com base em expressões-chave, das quais serão extraídas as ideias centrais e ancoragens (Lefèvre e Lefèvre, 2005; Lefèvre e Lefèvre, 2014).

A construção do DSC ocorreu com base em expressões-chave que agregavam ideias centrais consensuais no grupo pesquisado. As opiniões individuais e dissensos não compõem a construção do discurso. Eles, inclusive, não fizeram parte das narrativas da equipe de maneira significativa. Com o discurso-síntese construído, tecem-se comentários interpretativos de acordo com o referencial teórico adotado, tendo como parâmetro de comparação o preconizado pelo Ministério da Saúde no Caderno de Atenção Básica n. 39 (Brasil, 2014).

Foram, então, construídos sete DSC em torno de cinco ideias centrais: Concepção de saúde; Cultura assistencialista e a aceitação do Nasf-AB; Características e dinâmica do trabalho em equipe; Tecnologias de trabalho e a proposta do Nasf-AB: dos atos inúteis aos indispensáveis; Construção da agenda, planejamento, (des)vigilância em saúde e rede de serviços. Além disso, foram organizadas ideias centrais da equipe sobre os cinco elementos do processo de trabalho: agentes, objetos, instrumentos, produtos e finalidade.

Todas as fases desta pesquisa atenderam aos critérios éticos preconizados pela Resolução 466/2012 do Conselho Nacional de Saúde, incluindo a aprovação do projeto no Comitê de Ética em Pesquisa da Universidade de Pernambuco, de acordo com o parecer 1.622.483 e o Certificado de Apresentação para apreciação ética n. 55524012.2.0000.5207. O público-alvo foi convidado a participar desta pesquisa e assinaram o Termo de Compromisso Livre e Esclarecido. A Carta de anuência foi assinada pela Secretaria $\mathrm{Mu}$ nicipal de Saúde para acesso aos dados e aos sujeitos da pesquisa. 


\section{Resultados e Discussão}

\section{Identificando os elementos do processo de trabalho no Caderno de Atenção Básica n. 39 do Ministério da Saúde}

Houve uma apresentação à equipe dos elementos do processo de trabalho identificados no Caderno n. 39 (CAB n. 39) do Ministério da Saúde, a fim de utilizá-lo como parâmetro. Em seguida, foi feita a comparação entre os elementos do processo de trabalho preconizados com os elementos do processo de trabalho descrito pela própria equipe. Os resultados foram compilados no Quadro 1.

Um aspecto importante a se destacar sobre esses elementos é que o agente principal é a equipe do Nasf-AB; contudo, há outros agentes no processo, os quais também podem ser objetos.

Os instrumentos do trabalho do Nasf-AB abrangem tanto uma orientação clínica quanto de intervenção coletiva. Já os produtos, estão relacionados aos objetos, mas há que se destacar processos intermediários para que aqueles sejam efetivamente construídos, como: Formatos e dinâmicas de funcionamento do processo de trabalho mais efetivos; Ampliação de capacidade de resposta aos problemas de saúde; Ampliação do escopo de ofertas de cuidado; Ampliação do acesso aos recursos fora da Atenção Básica pelas ESFs; Maior articulação com a rede de serviços de saúde e outros setores; Critérios e fluxos com as equipes de saúde da família e gestão para organização da demanda; Ampliação de ações de promoção, recuperação, reabilitação da saúde e prevenção e tratamento de doenças, agravos, danos e riscos à saúde.

A finalidade do trabalho do Nasf- $\mathrm{AB}$, em resumo, é em defesa de uma vida saudável para as pessoas.

\section{Quadro 1}

\begin{tabular}{|c|c|c|c|c|}
\hline Agentes (e objetos) & Objetos & Instrumentos & Produtos & Finalidade \\
\hline $\begin{array}{l}\text { Indivíduos; } \\
\text { Família; } \\
\text { Comunidade; } \\
\text { Serviços da rede } \\
\text { de saúde e outros } \\
\text { setores; } \\
\text { ESF; } \\
\text { Equipes do } \\
\text { Consultório na Rua }\end{array}$ & $\begin{array}{l}\text { Processo de trabalho } \\
\text { da ESF; } \\
\text { Agravos, } \\
\text { danos, riscos, } \\
\text { vulnerabilidades, } \\
\text { determinantes da } \\
\text { saúde; } \\
\text { Aspectos biológicos, } \\
\text { sociais, psicológicos, } \\
\text { subjetivos, } \\
\text { comportamentais, } \\
\text { sanitários presentes no } \\
\text { território }\end{array}$ & $\begin{array}{l}\text { Saberes clínicos, sanitários, } \\
\text { epidemiológicos, sociopolíticos, } \\
\text { de núcleo e campo do saber; } \\
\text { Cogestão da coordenação e } \\
\text { longitudinalidade do cuidado; } \\
\text { Apoio matricial; } \\
\text { Vigilância em saúde; } \\
\text { Reuniões; } \\
\text { Clínica ampliada; } \\
\text { Espaço físico da Unidade e do } \\
\text { território; } \\
\text { Trabalho em equipe; } \\
\text { Atendimentos individuais } \\
\text { especializados, atendimentos } \\
\text { compartilhados, visitas } \\
\text { domiciliares, atividades em } \\
\text { grupo; } \\
\text { Suporte técnico-pedagógico, } \\
\text { educação permanente; } \\
\text { Territorialização; } \\
\text { Instrumentos de abordagem } \\
\text { familiar; } \\
\text { Instrumentos de planejamento }\end{array}$ & $\begin{array}{l}\text { Ambientes familiares } \\
\text { e comunitários mais } \\
\text { saudáveis; } \\
\text { Redução dos riscos, } \\
\text { danos, agravos e } \\
\text { vulnerabilidades; } \\
\text { Ampliação da } \\
\text { autonomia da } \\
\text { capacidade } \\
\text { dos sujeitos de } \\
\text { governarem a própria } \\
\text { vida; } \\
\text { Equipes de saúde } \\
\text { mais preparadas e } \\
\text { resolutivas }\end{array}$ & $\begin{array}{l}\text { Defesa da vida } \\
\text { saudável }\end{array}$ \\
\hline
\end{tabular}




\section{Identificando os elementos do processo de trabalho pelos grupos focais}

Os dois primeiros grupos focais detiveram-se na discussão de cada elemento do processo de trabalho e construíram os mapas analíticos, descrevendo-os. No Quadro 2, estão identificados os elementos do processo de trabalho do Nasf-AB segundo os profissionais da equipe.

\section{Quadro 2}

\begin{tabular}{|c|c|c|c|c|}
\hline Agentes (e objetos) & Objetos & Instrumentos & Produtos & Finalidade \\
\hline $\begin{array}{l}\text { Indivíduos, } \\
\text { equipamentos sociais } \\
\text { do território; } \\
\text { Ministério da Saúde; } \\
\text { Coordenação do } \\
\text { Nasf-AB; } \\
\text { Equipe de saúde da } \\
\text { família; } \\
\text { Serviços da rede de } \\
\text { saúde e outros setores }\end{array}$ & $\begin{array}{l}\text { Equipes de saúde } \\
\text { da família; } \\
\text { Pessoas; } \\
\text { Saúde; } \\
\text { Território; } \\
\text { Comunidades; } \\
\text { Equipamentos } \\
\text { sociais }\end{array}$ & $\begin{array}{l}\text { Instrumentos } \\
\text { burocráticos (planilhas } \\
\text { de acompanhamento de } \\
\text { casos, fichas E-SUS, } \\
\text { fichas de reuniões etc.); } \\
\text { Relatórios quantitativos } \\
\text { e qualitativos; } \\
\text { Agenda; } \\
\text { Computadores, internet, } \\
\text { datashow, whatsapp; } \\
\text { Instrumentos de } \\
\text { núcleo profissional, } \\
\text { como: Balança, } \\
\text { fita métrica, halter } \\
\text { labial, glicosímetro, } \\
\text { tensiômetro etc.; } \\
\text { Materiais de papelaria; } \\
\text { Espaços físicos da } \\
\text { Unidade de Saúde e da } \\
\text { comunidade; } \\
\text { Atendimentos; } \\
\text { Grupos; } \\
\text { Conhecimentos de } \\
\text { núcleo e campo do } \\
\text { saber; } \\
\text { Protocolos clínicos; } \\
\text { Rede de serviços; } \\
\text { Reuniões, escutas } \\
\text { qualificadas, } \\
\text { matriciamento; } \\
\text { Clínica ampliada, } \\
\text { territorialização }\end{array}$ & $\begin{array}{l}\text { Alunos de uma escola } \\
\text { inseridos no processo de } \\
\text { trabalho do NASF-AB; } \\
\text { A pessoa estar bem, sentir- } \\
\text { se bem; } \\
\text { Processo de inserção/ } \\
\text { reinserção social; } \\
\text { Olhar mais integral sobre } \\
\text { o cuidado; } \\
\text { Equipes de saúde mais } \\
\text { potencializadas }\end{array}$ & $\begin{array}{l}\text { Prevenção } \\
\text { de doenças e } \\
\text { promoção da } \\
\text { saúde; } \\
\text { Usuário melhor } \\
\text { de vida; } \\
\text { Atendimento } \\
\text { integral; } \\
\text { Ampliação da } \\
\text { visão clínica dos } \\
\text { profissionais; } \\
\text { Atividades } \\
\text { grupais; } \\
\text { Matriciar }\end{array}$ \\
\hline
\end{tabular}

Fonte: Os autores, com base nos grupos focais

NASF-AB - Núcleo Ampliado de Saúde da Família e Atenção Básica

\section{Agentes e objetos}

A concepção dos agentes e objetos do processo de trabalho foi se constituindo, assim como os demais elementos, ao longo das discussões no grupo focal, tendo como parâmetro a sistematização do processo de trabalho preconizado pelo Ministério da Saúde. A equipe identifica que esses dois elementos do processo de trabalho se confundem, ou seja, agentes são objetos e objetos são agentes. Pessoas, equipes de saúde, equipamentos sociais são exemplos de agentes que são objetos e vice-versa. Eles são objetos da atenção à saúde pelo Nasf-AB (no caso das pessoas e trabalhadores da equipe) ou objetos do matriciamento e da educação em saúde (no caso das equipes de saúde e 
equipamentos sociais). Paralelamente, são protagonistas do trabalho vivo, na medida em que decidem por determinadas ações e contribuem com suas experiências no processo de cuidado/trabalho.

Como apresentado no Quadro 2, há outros agentes que não são reconhecidos como objeto do processo de trabalho na comparação com o parâmetro. Entre estes, destacam-se o Ministério da Saúde e a coordenação do Nasf-AB. Contudo, o que se percebe é a concordância da concepção de agentes e objetos entre a equipe do Nasf-AB e o Caderno de Atenção Básica 39. A consequência dessa constatação é a necessidade de utilizar instrumentos de trabalho adequados para obter o produto desejado com a finalidade de defesa da vida saudável, que será discutido mais adiante.

\section{Produtos}

A concepção da equipe sobre os produtos do próprio trabalho guarda semelhança com os produtos do processo de trabalho que é parâmetro e enfatiza vivências específicas de sua prática de trabalho, como a relação com a escola, destacada no Quadro 2. Na comparação realizada pela equipe entre o que é preconizado e o que descreveram sobre os produtos do seu processo de trabalho, algumas conclusões foram obtidas por eles mesmos.

A primeira conclusão refere-se à equipe, a qual entendeu que, no seu processo de trabalho, os produtos intermediários, listados anteriormente, estão presentes nas suas práticas; entretanto, há destaque para a dificuldade na ampliação de ações de prevenção de doenças e promoção da saúde.

A equipe não pode afirmar que há ampliação da capacidade de resposta à maior parte dos problemas de saúde da população na atenção básica, tampouco que há maior efetividade de formatos organizativos e dinâmicas de funcionamento do processo de trabalho. Essa impossibilidade deve-se à incapacidade de mensurar e avaliar estes aspectos, por não haver comportamento e prática vigilante de modo organizado e sistemático nem por parte da equipe, nem da gestão.

Outra conclusão refere-se aos critérios e fluxos utilizados para a organização da demanda, os quais são considerados subjetivos, construídos por cada profissional com base em sua experiência e discutidos no momento das reuniões quando necessário. Contudo, a equipe pontua a necessidade de construção de critérios e fluxos mais objetivos e sistemáticos.

Essas constatações evidenciam um trabalho desarticulado, sem critérios pactuados de maneira objetiva e com pouca possibilidade de avaliar os resultados das intervenções. O processo de trabalho fragiliza-se, já que o fluxo básico de geração de um determinado produto, a partir de uma intervenção, não pode ser mensurado objetivamente. Percebe-se, pois, que os agentes en- 
volvidos (gestão, equipe de saúde da família e Nasf-AB) não trabalham de maneira coordenada e criteriosa, replicando mais um modelo de atenção à saúde reativo e fragmentado do que contínuo e integrado (Mendes, 2012).

\section{Instrumentos}

As tecnologias de trabalho detiveram longo tempo de debate, principalmente em relação à classificação em 'leves', 'leve-duras' e 'duras'. A concepção da equipe quanto aos instrumentos de trabalho do Nasf-AB está de acordo com o preconizado pelo $\mathrm{CAB}$ n. 39, com algumas considerações e exceção expostas a seguir.

A centralidade do Nasf-AB deveria, segundo a equipe, ser nas tecnologias leves e leve-duras, em função da natureza e da finalidade do trabalho, mais voltadas para a prevenção de doenças e promoção da saúde. Entretanto, as práticas da equipe acabam tendo uma centralidade burocrática direcionada para instrumentos de registro, preenchimento de fichas e planilhas que tomam grande parte do tempo dos profissionais e não são consideradas úteis.

O provimento de materiais e garantia de condições estruturais de trabalho sofre deficiência, como o espaço insuficiente para abarcar toda a equipe nas Unidades Básicas de Saúde e a não garantia de transporte para a equipe se locomover no território pela gestão municipal.

Alguns instrumentos não são utilizados pela equipe, como a 'territorialização', 'vigilância em saúde' e 'instrumentos de abordagem familiar'.

É importante reiterar que a consequência de se ter como objetos de trabalho a família, a comunidade e o território é possuir técnicas e instrumentos de intervenção em cada um deles. Aqui, evidencia-se mais um comprometimento do processo de trabalho: os instrumentos de diagnóstico do território e da família não são utilizados. Os outros dois pontos serão considerados mais adiante.

\section{Finalidades}

Algumas finalidades foram elencadas como próprias do trabalho do NasfAB: Prevenção de doenças e promoção da saúde, usuário melhor de vida, atendimento integral, ampliação da visão clínica dos profissionais, atividades grupais e 'matriciais'. Contudo, a ideia que se extrai dessas concepções dadas pela equipe é a de que 'finalidades' se confundem com 'meios' ou com 'produtos intermediários' do processo de trabalho. 'Ampliar a visão clínica dos profissionais' e o matriciamento, por exemplo, são referidos como instrumentos de trabalho e, ao mesmo tempo, como finalidade. Em contrapartida, a finalidade única que se tem como parâmetro é a 'defesa da vida saudável', que é a intencionalidade final do trabalho em saúde. Contudo, o que se percebe é que essa dificuldade de apontar, objetivamente, uma finalidade decorre mais 
por uma confusão de conceitos que da compreensão do processo de trabalho pela equipe.

\section{Um discurso coletivo: o 'eu' equipe}

As concepções e forma de organização do processo de trabalho da equipe Nasf-AB foi analisada, organizada em torno de ideias centrais e transformada em DSC. Estes revelam processos, dinâmicas, conceitos e desafios que envolvem o cotidiano das práticas da equipe, assim como os desejos, interesses e concepções dos profissionais acerca do seu processo de trabalho construídos e registrados segundo as reflexões em torno dos eixos dos mapas analíticos.

\section{Ideia central: concepção de saúde}

DSC 1: Adoto um trabalho na perspectiva da clínica ampliada, mais voltado para a promoção da saúde e prevenção de doenças. Ao mesmo tempo, vou de encontro com a concepção de um modelo médico assistencial. Não considero o conceito ampliado de saúde definido pela Organização Mundial da Saúde como algo alcançável e possível de concretizar nas práticas, mas sim a noção de 'equilíbrio' entre os aspectos psicossociais e biológicos que resultará no sentimento de 'bem-estar'.

A ancoragem desse discurso está nos mesmos fundamentos presentes na construção do CAB n. 39 e discutidos, neste trabalho, no tópico de 'processo de trabalho em saúde e os núcleos ampliados de saúde da família e atenção básica'. Está presente, também, no conceito de equilíbrio entre os aspectos fisiológicos e o ambiente em que o ser humano está inserido, herdando um pensamento hipocrático sobre o processo saúde-doença. Essa noção de saúde como equilíbrio que leva ao bem-estar é criticada pelo fato de não se excluir um processo patogênico ou não se suprir uma necessidade em decorrência de uma adaptabilidade ou 'equilíbrio' que leve a uma sensação de bem-estar (Almeida Filho, 2011).

Considerar a saúde sob esse ângulo pode abrir espaço para uma individualização do processo de cuidado (abordagens, técnicas etc.) deslocada de um contexto repleto de historicidade em que as pessoas fazem parte. Há, pois, um núcleo de contradição no âmbito da concepção de saúde que pode contribuir para explicar as práticas da equipe (Arouca, 2003).

\section{Ideia central: cultura assistencialista e a aceitação do Nasf-AB}

DSC 2: A forma de pensar, agir e demandar saúde pela população e profissionais das equipes de saúde da família segue a cultura assistencialista, curativa, focada em atendimentos, consultas e procedimentos, médico-centrada de modo geral. 
Entretanto, defendo que 'fazer ambulatório' não é meu papel e esse conflito gera tensionamentos que dificultam a relação com as equipes. Isso tem consequências na aceitação do meu trabalho e na resolutividade das ações de prevenção e promoção implementadas.

A cultura assistencialista presente nas demandas da população e das equipes de saúde da família (EqSFs) tensiona a relação com o Nasf-AB e estimula uma inflexão das práticas dos profissionais dessa equipe para uma lógica curativista, apesar de não necessariamente ser 'médico-centrada'. Suscita, então, a reflexão sobre a ampliação do escopo das ações e da retaguarda especializada da EqSF. A presença de profissionais de diferentes formações no território das EqSFs irão ampliar o escopo das ações de saúde, entretanto sem romper com o modelo hegemônico, com o diferencial de que o cuidado deixa de ser exclusivamente da figura do médico (Almeida, 2016).

A resolução dessa problemática vai além de questões tecnológicas e organizacionais internas ao processo de trabalho da equipe e exige enfrentamento em níveis 'meso' e 'macro', pois envolve múltiplos fatores. Entre eles, tem-se a formação dos profissionais das equipes e a lógica de produção do cuidado estimulada e exigida pela gestão dos serviços de saúde. Outro elemento importante é a concepção de saúde construída pela população, cujos focos são o acesso aos procedimentos diagnósticos e terapêuticos e os insumos relacionados a práticas de saúde (medicamentos, por exemplos). Configura-se, também, num problema 'macro', pois os fatores envolvidos estão inseridos num modo de produção econômico que determina as relações sociais, os aspectos ideológicos, condiciona comportamentos estimulados pelo consumismo. Esses aspectos explicam bem a forma como a saúde é demandada pela população (Arouca, 2003; Donnangelo, 1976).

\section{Ideia central: características e dinâmica do trabalho em equipe}

DSC 3: Uma das principais características da minha atuação é o trabalho em equipe e a centralidade no apoio matricial. Defino os principais instrumentos, comportamentos e arranjos organizacionais utilizados com base nessa lógica. Apesar disso, há fatores que dificultam a implementação dessa lógica: o número de equipes que apoio, a desvalorização das reuniões de equipe e, consequentemente, nossa atuação como 'porta de entrada' numa dinâmica inversa, me fazendo um 'apoiado' e não 'apoiador'.

Apesar de haver espaços para pactos que potencializem o trabalho em equipe, a dinâmica cotidiana não segue o preconizado pelas diretrizes e tampouco pelo que a equipe entende como bom funcionamento do processo de trabalho. Mesmo com sete anos de implantação do Nasf-AB em questão e com 
todas as atividades e esforços de sensibilização e esclarecimento sobre o papel do núcleo, há uma resistência para a sua forma de atuação. Ou seja, a desvalorização do espaço privilegiado das reuniões de equipe revela a ausência de um trabalho em equipe horizontal, guiado por um projeto comum, construído coletivamente (Peduzzi, 2001).

Tal fato corrobora com outros achados na literatura, em que o trabalho articulado não é uma prática comum ou, mais especificamente, sobre a dificuldade das equipes Nasf-AB em construírem Projetos Terapêuticos Singulares com as equipes de saúde da família (Reis et al., 2016; Vieira de Macedo et al, 2016).

A dinâmica inversa citada tem como pano de fundo a cultura assistencialista e exige do Nasf-AB uma prática fragmentada, centrada no atendimento clínico ambulatorial, como também evidenciado em outros trabalhos. Ou seja, enquanto se relatam os esforços para configuração de uma equipe 'Nasf equipe matricial', as relações com os diversos atores do processo de trabalho criam um ambiente de tensão. Desse modo, é difícil manter vivo esse arranjo e há uma pressão para a reprodução de uma equipe 'Nasf assistencial-curativista', cuja noção de suporte restringe-se ao apoio técnico-assistencial (Reis et al., 2016; Shimizu e Fragelli, 2016; Nascimento, 2014; Merhy, 2014).

\section{Ideia central: tecnologias de trabalho e a proposta do Nasf-AB: dos atos inúteis aos indispensáveis}

DSC 4: A minha proposta de trabalho deve ser centrada nas tecnologias leves, devido à natureza do meu trabalho. Apesar disso, há um conjunto de instrumentos que considero puramente burocráticos fazendo parte do meu trabalho de forma central, que são caracterizados de tecnologias leve-duras como: planilhas de acompanhamento de casos, fichas de reuniões, fichas do E-SUS. É um trabalho morto, tudo que é preenchido é enviado para a gestão, que não dá resposta dessas informações, não as gerencia para utilização do processo de trabalho da equipe.

DSC 5: Contudo, há práticas que são essenciais, como os matriciamentos, reuniões de discussão de caso, reuniões da equipe Nasf-AB para organizar o trabalho, grupos para atividades de promoção e prevenção, que inclusive necessitam ser ampliados quantitativamente. Um trabalho que considero essencial é o planejamento do processo de trabalho. Sua implementação qualificaria as ações e evitaria os constantes fracassos que desmotivam as equipes de saúde em relação ao trabalho com grupos.

Percebe-se um choque entre as concepções da equipe, suas práticas e as dos outros agentes que compõem o processo de trabalho do Nasf-AB, principalmente, nesse caso, a 'gestão'. Enquanto é reconhecida a centralidade das tecnologias leves e leve-duras devido à natureza do processo de trabalho do 
Nasf-AB, o processo de burocratização fortalece essa centralidade em um trabalho morto (Merhy, 2014). O agravamento dessa situação revela-se quando o produto das atividades burocráticas não é utilizado para a organização do processo de trabalho, especialmente nas atividades de planejamento e avaliação.

As atividades de prevenção e promoção da saúde, apesar de consideradas indispensáveis, são pouco implementadas pela equipe, a qual relata desmotivação com os 'constantes fracassos' nas tentativas de pôr em prática essas ações. Há discordância e uma crítica ao modo como grupos de 'hiperdia' (que, nesse caso, se refere a uma nomenclatura dada aos grupos 'terapêuticos' de prevenção e de promoção da saúde voltados para a população com hipertensão arterial sistêmica e diabetes mellitus) são conduzidos pelas EqSFs. Estas, no lugar de serem um lócus de práticas de prevenção de doenças e promoção da saúde, acabam por reproduzir a lógica assistencialista quando focam na 'transcrição de receitas de medicamentos'.

Um dos fatores condicionantes dos fracassos das ações de prevenção de doenças e promoção da saúde pode ser identificado na análise dos elementos do processo de trabalho da equipe. Realizar o diagnóstico territorial é fundamental para conhecer as demandas da população; entretanto, como já observado, o uso de ferramentas para este fim não fazem parte do cotidiano da equipe. Do mesmo modo, todo ato de coleta de dados e registros de atividades realizadas pela equipe (considerados burocráticos) só são vistos como inúteis porque não se mobilizam esforços para aproveitar seus resultados no planejamento e avaliação das ações. Isso aumenta a possibilidade de ações fracassadas, que desmotivam a equipe e comprometem todo processo de trabalho.

\section{Ideia central: construção da agenda, planejamento, (des)vigilância em saúde e rede de serviços}

DSC 6: A maior parte das demandas que chegam até mim são clínicas, exigem uma abordagem assistencialista. A construção da agenda acontece, principalmente, através das demandas que chegam a mim pelas reuniões de equipe. Em segundo lugar, através de uma forma que considero desorganizada, que são repasses de maneira informal (por 'receituários', telefone, nos encontros de corredores). Em terceiro lugar, são demandas vindas da rede de serviços e, por último, de demandas solicitadas diretamente pela gestão.

DSC 7: 'Algo que sinto muita falta é o planejamento e gestão do processo de trabalho baseado na realidade epidemiológica e sociodemográfica do território adscrito, assim como o uso de critérios ou instrumentos que classifiquem e organizem as demandas discutidas nas reuniões de equipe. 
Os discursos acima caracterizam um modo de atuação desorganizado, com baixa - ou nenhuma - possibilidade de alcançar níveis de resolutividade que consigam dar conta dos problemas de saúde da população adscrita, já que não se acompanha de forma clara e sistemática o perfil epidemiológico, demográfico, além dos aspectos culturais e econômicos do território. Isso impossibilita a construção de objetivos, metas, formas de intervenção, assim como impede o processo de monitoramento e avaliação das ações implementadas.

A construção da agenda da equipe, conforme citado, revela que a maior parte das demandas, que são clínicas, tem origem nas reuniões de equipe e estas, conforme já discutido, são desvalorizadas como espaço de discussão e organização do processo de trabalho. O que se percebe é a soma de fatores que engrenam um modelo de atenção 'reativo', 'episódico', fragmentado e sem sustentação pelas informações da situação de saúde das pessoas (Mendes, 2012).

\section{Os discursos em síntese}

O conjunto das ideias centrais e seus respectivos discursos do sujeito coletivo apresentam respostas para a pergunta central do presente estudo: Como se organiza o processo de trabalho da equipe do Núcleo Ampliado de Saúde da Família e Atenção Básica?

As concepções expressadas no discurso da equipe são de um 'dever ser', pautadas pela clínica ampliada e pelo trabalho em equipe. O matriciamento é colocado como tecnologia central e sua utilização tem espaço privilegiado nas reuniões de equipe. Essa forma de entender o processo de trabalho corrobora com o que se preconiza no Caderno de Atenção Básica n. 39 e vai de encontro com a lógica anatomofisiológica, hospitalocêntrica hegemônica no campo da atenção à saúde.

Contudo, concretizar o 'dever ser' exige ir além das concepções para transformá-las em 'fazeres', por meio de valises tecnológicas e de inter-relacionamentos com outras equipes de saúde, com diversos profissionais e com a população usuária dos serviços de saúde. Existe uma forma de matriciar que se tenta implementar, mas com pouco sucesso; o trabalho torna-se fragmentado e com foco assistencialista. Em geral, as reuniões são pouco valorizadas pelas equipes de saúde e não há sucesso na construção de pactos a respeito do processo de trabalho, bem como sobre as decisões de intervenções no território. Isso revela uma atuação distante do que se concebe como ideal pela própria equipe.

As justificativas para tal situação giram em torno da relação com a gestão, que contribui de maneira insuficiente para o apoio ao planejamento, não fornece estrutura física nem recursos adequados. Ademais, estimula a buro- 
cratização do trabalho, pois, ao invés de deslocar o foco para a utilização das tecnologias leves, volta-se para as tecnologias leve-duras burocráticas. Outra explicação para a situação vigente é a da relação com as equipes de saúde da família, por estas terem dificuldade de reconhecimento e de aceitação do tipo de trabalho do Nasf-AB, seguindo a lógica assistencialista e curativista. Por fim, a relação com a população valoriza o paradigma da atenção à saúde voltada para o assistencialismo e curativismo, centrada em procedimentos.

Entretanto, cabe também ressaltar aspectos inerentes à equipe para não restringir a análise do processo às relações com atores externos ao grupo. A clínica ampliada, citada como diretriz necessária ao trabalho da equipe, exige instrumentos que intermedeiem as intervenções sobre o objeto e o agente do trabalho. Instrumentos que analisem a realidade das pessoas no âmbito individual e familiar, assim como a dinâmica territorial e o perfil epidemiológico, demográfico, cultural e econômico não são utilizados para orientar a organização do processo de trabalho e as intervenções necessárias a serem realizadas. Chama a atenção a não utilização de instrumentos de abordagem familiar numa equipe que tem a família como objeto de trabalho. Também é alarmante evidenciar a condução do trabalho sem estar orientado com base na vigilância em saúde.

O trabalho é mais voltado para demandas assistenciais como consequência de um comportamento reativo, provocado pela equipe de saúde, que as solicitam, com escasso ou nenhum planejamento e monitoramento tanto da situação de saúde do território como, consequentemente, da resolutividade da equipe Nasf-AB. Contudo, há ações conjuntas que são implementadas pela equipe, assim como ações técnico-pedagógicas, a despeito de um trabalho mais voltado para ações assistenciais. Desse modo, pode-se classificar a equipe como um Nasf-AB 'semimatricial'.

Há, pois, fatores externos que dificultam o modelo preconizado para atuação do Nasf-AB. Além dos já citados, tem-se a fragilidade de vínculos empregatícios dos profissionais da equipe; no núcleo estudado, apenas um deles tem vínculo estável. Existem os fatores internos que perpassam desde a concepção de saúde da equipe, passando pelas formas de organização das demandas até o instrumental utilizado no trabalho.

\section{Considerações Finais}

O exercício de análise do processo de trabalho revela concepções, impressões, comportamentos e contradições da equipe nas suas práticas cotidianas e num ambiente de reflexão e debate que constrói possibilidades de transformações concretas, caso haja uma adequada condução para seu desdobramento. Apesar do entendimento da equipe sobre seu processo de trabalho ir ao encontro de um modelo de atuação do Nasf-AB preconizado nacionalmente, 
suas práticas concretas correm no sentido contrário, se distanciam, tanto por fatores externos à equipe, quanto por fatores internos.

Alguns problemas destacam-se no processo de trabalho desta equipe: a dificuldade de implementar ações efetivas na prevenção de doenças e promoção da saúde; a não utilização de tecnologias de análise e intervenção familiar e populacional; a escassa prática de planejamento das ações. Esses pontos são necessários para o alcance de resolutividade no trabalho do Nasf-AB e configuram um escopo de atuação para a transformação do processo de trabalho.

Para que os resultados almejados pela equipe sejam alcançados, outros aspectos necessitam ser superados: a condução da gestão do processo de trabalho precisa ser permanente sobre os pontos aqui discutidos, integrando o Nasf-AB, a equipe de saúde da família, a comunidade e os gestores, de modo que haja uma sistematização de informação e de planejamento estratégico, necessários para a atuação dos profissionais nas mudanças e aperfeiçoamento do processo de trabalho voltado para outro paradigma.

Para que todos os esforços tenham sucesso, é de extrema importância a atenção para as condições de trabalho da equipe, para as causas das desmotivações relatadas e para a saúde dos trabalhadores, valorizando o trabalho interprofissional e as práticas colaborativas em saúde no processo de fortalecimento e consolidação da ESF e do Sistema Único de Saúde.

\section{Colaboradores}

Arthur Grangeiro do Nascimento conduziu a pesquisa de campo e atuou em todas as etapas, desde a concepção do projeto de pesquisa até a construção do artigo. Joselma Cavalcanti Cordeiro orientou a pesquisa, participou da pesquisa de campo e fez a revisão crítica do artigo. Não há conflito de interesses.

\section{Financiamento}

Não houve financiamento externo. 


\section{NÚCLEO AMPLIADO DE SALUD DE LA FAMILIA Y ATENCIÓN BÁSICA: ANÁLISIS DEL PROCESO DE TRABAJO}

Resumen El artículo tiene el objetivo de analizar el proceso de trabajo de un equipo del Núcleo Ampliado de Salud de la Familia y Atención Básica ubicado en un municipio del Estado de Pernambuco, Brasil. Se trata de un estudio de caso con enfoque cualitativo, de carácter analítico-descriptivo. Las técnicas empleadas para la recogida de datos fueron los grupos focales y mapas analíticos; para organización y análisis, se adoptó la técnica del Discurso del Sujeto Colectivo. El análisis del proceso de trabajo reveló concepciones en el discurso del equipo de un 'deber ser' pautado por lo propuesto por el Ministerio de Salud de Brasil. Sin embargo, se identificaron los siguientes aspectos: poco éxito en ejecutar el apoyo matricial; no se logra obtener éxito en la construcción de acuerdos sobre el proceso de trabajo; el trabajo es fragmentado y con foco asistencialista; no se utilizan tecnologías de análisis e intervención familiar y poblacional. Se observó además una escasa práctica de planificación de las acciones. Esto revela una actuación distante de lo que se concibe como adecuado por el propio equipo. Se identificaron factores problemáticos, internos y externos al equipo. Se indica partir de un análisis del proceso de trabajo realizado por el propio equipo, contribuyendo para obtener una mayor capacidad de resolución.

Palabras clave atención primaria de la salud; trabajo en salud; personal de salud; Estrategia de Salud de la Familia; investigación cualitativa.

\section{Referências}

ALMEIDA FILHO, Naomar. Saúde como campo de práticas. In: ALMEIDA FILHO, Naomar. O que é Saúde? Rio de Janeiro: Editora Fiocruz, 2011. p 105-123.

ALMEIDA, Erika R. A gênese dos núcleos de apoio à saúde da família. 198 fl. 2016. Tese (Doutorado em Saúde Pública), Instituto de Saúde Coletiva, UFBA, Salvador, 2016.

AROUCA, Antônio S. O dilema preventivista: contribuição para a compreensão e crítica da Medicina Preventiva. São Paulo: UNESP; Rio de Janeiro: Fiocruz, 2003.

BACKES, Dirce S. et al. Grupo focal como técnica de coleta e análise de dados em pesquisas qualitativas. Mundo da Saúde, São Paulo, v. 35, n. 4, p. 438-442, 2011.

BARROS, Juliana O. et al. Estratégia do apoio matricial: a experiência de duas equipes do Núcleo de Apoio a Saúde da Família da cidade de São Paulo. Ciência \& Saúde Coletiva, Rio de Janeiro, v. 20, n. 9, p. 2847-2856, 2015. Disponível em: <http://www.scielo.br/scielo.
php?pid=S1413-81232015000902847\&script=sci_ abstract\&tlng=pt>. Acesso em: 09 ago. 2017.

BEDRIKOW, Rubens; CAMPOS, Gastão W. S. História da clínica e a atenção básica: o desafio da ampliação. 1. ed. São Paulo: Hucitec, 2014.

BRASIL. Ministério da Saúde. Gabinete do Ministro. Portaria n. 2.436, de 21 de setembro de 2017. Aprova a Política Nacional de Atenção Básica, estabelecendo a revisão de diretrizes para a organização da Atenção Básica, no âmbito do Sistema Único de Saúde (SUS). Diário Oficial da República Federativa do Brasil, Poder Executivo, Brasília, DF, 22 set. 2017.

BRASIL. Ministério da Saúde. Núcleo de Apoio à Saúde da Família: ferramentas para gestão e para o trabalho cotidiano. v. 1. Brasília: Ministério da Saúde, 2014. 118 p. (Cadernos de Atenção Básica, n. 39)

CECCIM, Ricardo B.; FEUERWERKER, Laura C. M. Mudança na graduação das profissões de saúde sob o eixo da integralidade. Cadernos de Saúde Pública, Rio de Janeiro, v. 20, n. 5, 
p. 1400-1410, set.-out., 2004. Disponível em: $<$ http://www.scielo.br/scielo.php?script=sci_ arttext\&pid=S0102-311X2004000500036>. Acesso em: 12 ago. 2017.

DENZIN, Nornam K.; LINCOLN, Yvonna S. O planejamento da pesquisa qualitativa: teorias a abordagens. 2. ed. Porto Alegre: Artmed, 2006.

DONNANGELO, Maria C. F. Saúde e sociedade. São Paulo: Duas cidades, 1976.

FRANCO, Tulio B.; MERHY, Emerson E. Trabalho em saúde. In: PEREIRA, Isabel B. e LIMA, Júlio C. F. (orgs.). Dicionário da educação profissional em saúde. Rio de Janeiro: EPSJV/Fiocruz, 2008. p. 278-284.

FRANCO, Tulio B.; MERHY, Emerson E. Mapas analíticos: um olhar sobre a organização e seus processos de trabalho. In: MERHY, Emerson E.; FRANCO, Tulio. B. (orgs.). Trabalho, produção do cuidado e subjetividade em saúde. São Paulo: Hucitec, 2013, p. 285-306.

LANCMAN, Selma et al. Estudo do trabalho e do trabalhar no Núcleo de Apoio à Saúde da Família. Revista de Saúde Pública, São Paulo, v. 47, n. 5 , p. $968-75,2013$.

LEFÈVRE, Fernando; LEFÈVRE, Ana M. C. Discurso do sujeito coletivo: representações sociais e intervenções comunicativas. Texto \& Contexto Enfermagem, Florianópolis, v. 23, n. 2, p. 502-507, abr.-jun., 2014.

LEFÈVRE, Fernando; LEFÈVRE, Ana M. C. O discurso do sujeito coletivo: um novo enfoque em pesquisa qualitativa (desdobramentos). Caxias do Sul: Educs, 2005.

MENDES, Eugenio V. O cuidado das condições crônicas na atenção primária à saúde: o imperativo da consolidação da estratégia da saúde da família. 1. ed. Brasília: Organização Pan-Americana da Saúde. 2012.
MENDES-GONÇALVES, Ricardo B. Práticas de saúde: processos de trabalho e necessidades. São Paulo: Cefor, 1992.

MERHY, Emerson E. A micropolítica do trabalho vivo em ato: uma questão institucional e território de tecnologias leves. In: MERHY, Emerson E. (org.). Saúde: a cartografia do trabalho vivo. São Paulo: Hucitec, 2014. p. 19-40.

MERHY, Emerson E. A perda da dimensão cuidadora na produção da saúde: uma discussão do modelo assistencial e da intervenção no seu modo de trabalhar a assistência. In: MERHY, Emerson E.; FRANCO, Tulio. B. (Orgs.). Trabalho, produção do cuidado e subjetividade em saúde. São Paulo: Hucitec, 2013, p. 68-94.

MERHY, Emerson E. Em busca do tempo perdido: a micropolítica do trabalho vivo em saúde. In: MERHY, Emerson E.; ONOCKO, Rosana (orgs.). Agir em saúde: um desafio para o público. São Paulo: Hucitec, 1997. p. 71-112.

MOURA, Renata H.; LUZIO, Cristina A. O apoio institucional como uma das faces da função de apoio do Núcleo de Apoio à Saúde da Família. Interface (Botucatu), Botucatu, v. 18, supl. 1, p. 957-70, 2014.

NASCIMENTO, Cynthia M. B. Núcleo de apoio à saúde da família: uma análise da atenção à saúde em municípios da Região Metropolitana do Recife. 182 fl. Tese (Doutorado em Saúde Pública) - Centro de Pesquisas Aggeu Magalhães, Fundação Oswaldo Cruz, Recife, 2014.

PASQUIM, Heitor M.; ARRUDA, Marcel S. B. Núcleo de apoio à saúde da família: revisão narrativa sobre o apoio matricial na atenção básica. Corpus et Scientia, Rio de Janeiro, v. 9, n. 2, p. 34-44, jul.-dez., 2013.

PEDUZZI, Marina. Equipe multiprofissional de saúde: conceito e tipologia. Revista Saúde Pública, São Paulo, v. 35, n. 1, p. 103-9, 2001. Disponível em: <http://www.scielo.br/scielo. php?pid=S0034-89102001000100016\&script=sci abstract\&tlng $=$ pt $>$. Acesso em: 02 ago. 2017. 
REIS, Mary L. et al. Avaliação do trabalho multiprofissional do Núcleo de Apoio à Saúde da Família. Texto \& Contexto Enfermagem, Florianópolis, v. 25, n. 1: e2810014, 2016. Disponível em: <http://www.scielo.br/scielo. php?pid=S0104-07072016000100321\&script $=$ sci_ abstract\&tlng=pt $>$. Acesso em: 10 ago. 2017.

SHIMIZU, Helena E.; FRAGELLI, Thais B. O. Competências profissionais essenciais para o trabalho no Núcleo de Apoio à Saúde da Família. Revista Brasileira de Educação Médica, Rio de Janeiro, v. 40, n. 2, p. 216-225, 2016. Disponível em: <http://www.scielo.br/scielo. php?pid=S0100-55022016000200216\&script $=$ sci_ abstract\&tlng $=$ pt $>$. Acesso em: 10 set. 2017.
UCHIMURA, Kátia Y.; BOSI, Maria L. M. Qualidade e subjetividade na avaliação de programas e serviços em saúde. Cadernos de Saúde Pública, Rio de Janeiro, v. 18, n. 6, p. 1561-1569, Dec. 2002.

VIEIRA DE MACEDO, Mirnis A. et al. Análise do processo de trabalho no núcleo de apoio à saúde da família em município do nordeste brasileiro. Revista Gerencia y Politicas de Salud, Bogotá, v. 15, n. 30, p. 194-211, jan.-jun. 2016. Disponível em: <http://www.scielo.org.co/ scielo.php?script $=$ sci_abstract $\&$ pid $=$ S1657$70272016000100014 \& \operatorname{lng}=$ pt \&nrm $=$ iso $>$. Acesso em: 24 set. 2017.

YIN, Robert K. Estudo de caso: planejamento e métodos. 4. ed. Porto Alegre: Bookman; 2010. 